\title{
Adult Onset Spinocerebellar Ataxia in a Canadian Movement Disorders Clinic
}

\author{
Scott Kraft, Sarah Furtado, Ranjit Ranawaya, Jillian Parboosingh, Stacey Bleoo, \\ Karen McElligott, Peter Bridge, Sian Spacey, Shyamal Das, Oksana Suchowersky
}

\begin{abstract}
Background: The spinocerebellar ataxias (SCAs) are a genetically and clinically heterogeneous group of neurodegenerative disorders. Relative frequencies vary within different ethnic groups and geographical locations. Objectives: 1) To determine the frequencies of hereditary and sporadic adult onset SCAs in the Movement Disorders population; 2) to assess if the fragile X mental retardation gene 1 (FMR1) premutation is found in this population. Methods: A retrospective chart review of individuals with a diagnosis of adult onset SCA was carried out. Testing for SCA types 1, 2, 3, 6, 7, and 8, Dentatorubral-pallidoluysian atrophy (DRPLA), Friedreich ataxia and the FMR1 expansion was performed. Results: A total of 69 patients in 60 families were identified. Twenty-one $(35 \%)$ of the families displayed autosomal dominant and two (3.3\%) showed autosomal recessive (AR) pattern of inheritance. A positive but undefined family history was noted in nine (15\%). The disorder appeared sporadic in 26 patients $(43.3 \%)$. In the AD families, the most common mutation was SCA3 (23.8\%) followed by SCA2 (14.3\%) and SCA6 (14.3\%). The SCA1 and SCA8 were each identified in $4.8 \%$. FA was found in a pseudodominant pedigree, and one autosomal recessive pedigree. One sporadic patient had a positive test (SCA3).Dentatorubral-pallidoluysian atrophy and FMR1 testing was negative. Conclusion: A positive family history was present in $53.3 \%$ of our adult onset SCA patients. A specific genetic diagnosis could be given in $61.9 \%$ of dominant pedigrees with SCA3 being the most common mutation, followed by SCA2 and SCA6. The yield in sporadic cases was low. The fragile $\mathrm{X}$ premutation was not found to be responsible for SCA.
\end{abstract}

RÉSUMÉ: Ataxie spinocérébelleuse débutant chez l'adulte dans une clinique de désordres du mouvement au Canada. Contexte: Les ataxies spinocérébelleuses (ASCs) constituent un groupe hétérogène de maladies neurodégénératives tant au point de vue génétique qu'au point de vue clinique. Leur fréquence relative est très variable selon le groupe ethnique et le lieu géographique. Objectifs: 1) déterminer la fréquence d'ASCs héréditaires et sporadiques débutant chez l'adulte chez des patients fréquentant une clinique de désordres du mouvement ; 2) évaluer si on retrouve chez ces patients des prémutations du gène FMR1 causant le syndrome de retard mental du X fragile. Méthodes: Nous avons procédé à une revue rétrospective de dossiers de patients chez qui un diagnostic d'ASC de l'adulte a été posé. Des tests de biologie moléculaire ont été faits pour détecter des anomalies des gènes responsables de l'ASC de type 1,2,3,6,7 et 8, de l'atrophie dentato-rubro-pallido-luysienne (ADRPL), de l'ataxie de Friedrich (AF) ainsi que l'expansion de FMR1. Résultats: 69 patients appartenant à 60 familles différentes ont été identifiés. Chez 21 familles (35\%), l'hérédité était autosomique dominante (AD) et chez $2(3,3 \%)$ l'hérédité était autosomique récessive (AR). Une histoire familiale positive mal définie était présente chez 9 familles (15\%). La maladie semblait sporadique chez 26 patients $(43,3 \%)$. Chez les familles où l'hérédité était $\mathrm{AD}$, la mutation la plus fréquents était une mutation du gène ASC3 (23,8\%) suivie d'ASC2 (14,3\%) et d'ASC6 (14,3\%). Une mutation du gène ASC1 et ASC8 a été identifiée chez 4,8\% des patients. Une mutation du gène de l'AF a été identifiée dans un pedigree où la maladie était pseudo dominante et dans un où la maladie était $\mathrm{AR}$. Chez un cas sporadique on a trouvé une mutation du gène ASC3. Les tests pour l'ADRPL et le FMR1 étaient négatif. Conclusion: Une histoire familiale positive était présente chez $53,3 \%$ des patients atteints d'ASC adulte. Un diagnostic génétique spécifique a pu être établi chez $61,9 \%$ des pedigrees où l'hérédité était dominante et une mutation du gène ASC3 était l'anomalie la plus fréquente, suivie d'ASC2 et d'ASC6. Le rendement était faible chez les cas sporadiques. La prémutation du gène responsable du syndrome du X fragile n'était pas responsable de l'ASC chez nos cas.

Can. J. Neurol. Sci. 2005; 32: 450-458

The spinocerebellar ataxias (SCAs) are a large group of neurological disorders which may be hereditary or sporadic. The core clinical features of gait and limb ataxia are manifestations of degenerations of the cerebellum and its connections. Other neurological systems are variably involved producing features such as extraocular movement abnormalities, pyramidal tract dysfunction, sensory loss, bulbar dysfunction, and movement disorders such as parkinsonism, dystonia and tremor. ${ }^{1}$

The dominantly inherited SCAs were classified in the past according to a scheme suggested by Harding. ${ }^{1}$ In this system, the autosomal dominant cerebellar ataxias (ADCA) were separated clinically into three types. In addition to cerebellar ataxia, ADCA I patients had variable degrees of dementia, supranuclear ophthalmoplegia, optic atrophy, and extrapyramidal features. Patients classified as having ADCA Type II developed pigmentary retinal degeneration which could precede the development of the ataxia. Autosomal dominant cerebellar

From the Department of Clinical Neurosciences, University of Calgary (SK, SF, RR, OS), Department of Medical Genetics, University of Calgary (JP, SB, KM, PB, OS), Calgary, Alberta, Canada; Division of Neurology, Department of Medicine, University of British Columbia (SS), Vancouver, British Columbia, Canada; Bangur Neurological Institute (SD), Kolkata, India.

ReCeived February 9, 2004. AcCePted in Final form June 26, 2005.

Reprint requests to: Scott Kraft, The Movement Disorders Program, Dept. of Clinical Neurosciences, University of Calgary, 3350 Hospital Dr. NW, Calgary, Alberta, Canada $\mathrm{T} 2 \mathrm{~N} 4 \mathrm{~N} 1$ 
Table 1: Summary of the Dominantly Inherited SCAs

\begin{tabular}{lll}
\hline Name & Locus & Clinical Features in Addition to Gait and Limb Ataxia \\
\hline SCA1 $^{2,89,90}$ & $6 \mathrm{p} 23$ & Oculomotor defects, muscle weakness, decreased vibration sense, pyramidal signs \\
\hline SCA2 $^{3-5,52,68-70,91,92}$ & $12 \mathrm{q} 23-\mathrm{q} 24.1$ & Slow saccades, hypotonia, Parkinsonism \\
\hline SCA3 $^{6,93-97}$ & $14 \mathrm{q} 24.3-\mathrm{q} 32$ & $\begin{array}{l}\text { Type I - pyramidal and extrapyramidal findings, progressive external ophthalmoplegia and } \\
\text { minor cerebellar deficits } \\
\text { Type II - cerebellar and pyramidal deficits, without extrapyramidal signs with or without } \\
\text { progressive external ophthalmoplegia }\end{array}$ \\
& $\begin{array}{l}\text { Type III - distal symmetrical muscle atrophy with cerebellar findings with or without } \\
\text { progressive external ophthalmoplegia and pyramidal signs } \\
\text { Type IV - Parkinsonism and peripheral neuropathy }\end{array}$
\end{tabular}

\begin{tabular}{|c|c|c|}
\hline SCA4 $4^{20,21}$ & $16 \mathrm{q} 22.1$ & $\begin{array}{l}\text { Two families - one with sensory neuropathy and the other with dysarthria and no sensory } \\
\text { neuropathy }\end{array}$ \\
\hline $\mathrm{SCA}^{22}$ & $11 \mathrm{p} 11-\mathrm{q} 11$ & Predominantly cerebellar. Very slow progression \\
\hline $\mathrm{SCA}^{7}$ & $19 \mathrm{p} 13$ & Predominantly cerebellar \\
\hline$\underline{\mathrm{SCA}} 7^{8,9,98}$ & 3p21.1-p12 & Pigmentary retinopathy \\
\hline SCA $8^{15}$ & $13 \mathrm{q} 21$ & Spasticity and decreased vibration sense. Controversial \\
\hline $\mathrm{SCA}^{37}$ & Reserved & \\
\hline SCA10 $10^{99,100}$ & $22 \mathrm{q} 13$ & Seizures in 20 to $100 \%$ \\
\hline SCA1123 & $15 q 14-q 21.3$ & Predominantly cerebellar \\
\hline SCA12 13 & $5 q 31-q 33$ & Early upper extremity tremor and late dementia \\
\hline $\mathrm{SCA}_{13}{ }^{24}$ & $19 \mathrm{q} 13.3-\mathrm{q} 13.4$ & Childhood onset. Mental retardation \\
\hline$\underline{\mathrm{SCA} 14^{25,26}}$ & 19q13.4-qter & Predominantly cerebellar but axial myoclonus if younger age of onset \\
\hline SCA15 34,101 & 3 p26.1-p25.3 & Predominantly cerebellar. Postural/action tremor. Very slow progression \\
\hline $\mathrm{SCA} 16^{27}$ & $8 \mathrm{q} 22.1-\mathrm{q} 24.1$ & Predominantly cerebellar with head tremor \\
\hline SCA17 10,11 & $6 q 27$ & Intellectual deterioration \\
\hline SCA1 $18^{28}$ & $7 q 22-q 32$ & Sensory loss, pyramidal tract signs, muscle weakness \\
\hline SCA1929,102 & $1 \mathrm{p} 21-\mathrm{q} 21$ & Mild ataxia with cognitive impairment, myoclonus, and a low frequency postural tremor \\
\hline$\underline{\mathrm{SCA}} 20^{33}$ & $11 \mathrm{p} 13-\mathrm{q} 11$ & Palatal tremor, dysphonia, and dentate nucleus calcification \\
\hline SCA $21^{30,103}$ & $7 \mathrm{p} 21.3-\mathrm{p} 15.1$ & $\begin{array}{l}\text { Hyporeflexia, postural tremor, parkinsonism, cognitive impairment. Extraocular movements generally } \\
\text { normal }\end{array}$ \\
\hline SCA22 $2^{31}$ & $1 \mathrm{p} 21-\mathrm{q} 23$ & Predominantly cerebellar with hyporeflexia. Slow progression \\
\hline $\mathrm{SCA} 23^{35}$ & 20p13-p12.2 & No published information available \\
\hline $\mathrm{SCA} 24^{36}$ & None & Likely recessive. Saccadic intrusions, increased saccadic speed, sensory neuropathy, and myoclonus \\
\hline $\mathrm{SCA} 25^{32}$ & $2 \mathrm{p} 21-\mathrm{p} 13$ & Sensory neuropathy \\
\hline
\end{tabular}

ataxias Type III was described as a relatively pure cerebellar syndrome.

At present, classification of the SCAs is largely based on genetic mutations rather than clinically defined syndromes. A summary of the chromosomal loci and clinical characteristics of the currently described SCAs is presented in Table 1 . In the SCAs where a genetic defect has been identified, the abnormality has thus far involved expansion of unstable repeat sequences of deoxyribonucleic acid (DNA). The most common expansions are of triplet CAG (cytosine/adenine/guanine) sequences which encode polyglutamine within the protein. This is the case for SCA types 1, 2, 3, 6, 7, and 17.2-11 Dentatorubral-pallidoluysian atrophy (DRPLA) is another autosomal dominant ataxic disorder that has been found to result from expansion of a polyglutamine sequence. $^{12}$

Expansion of trinucleotide repeats in non-coding regions of a gene may also lead to disease. Although the genetic abnormality in SCA12 is a CAG repeat, it appears to occur outside of the translated portion of the gene so a polyglutamine tract is not created. ${ }^{13}$ Friedreich ataxia (FA) is caused by an intronic GAA triplet repeat expansion. ${ }^{14}$ SCA8 is thought to be the result of a non-coding cytosine/thymine/guanine (CTG) expansion, although the significance of the expansion has been questioned. ${ }^{15-18}$ In the case of SCA10 the expansion is of an ATTCT (adenine/thymine/thymine/cytosine/thymine) pentanucleotide repeat. ${ }^{19}$ The pathologic repeat numbers in these disorders are generally much larger when it affects the noncoding, rather than the coding regions.

For many dominantly inherited SCA families a chromosomal locus for the disorder has been described but a specific genetic defect has not yet been discovered. This is the case for SCA types $4,5,11,13$ to 16,18 to 22 and $25 .{ }^{20-34}$ The human genome organisation (HUGO) Gene Nomenclature Committee website lists a locus for SCA23 but without clinical data. ${ }^{35}$ The disorder 
currently labelled SCA24 appears to be recessive. ${ }^{36}$ The label SCA9 is currently reserved. ${ }^{37}$

As is common with most genetic disorders, the relative frequencies of the SCAs vary within different populations. To date, there is no published data regarding the distribution of the SCAs or diagnostic yield of SCA testing in a Canadian population; this paper aims to provide such information.

Recently, a syndrome consisting of tremor, cerebellar dysfunction, parkinsonism, and cognitive decline associated with the fragile $\mathrm{X}$ premutation has been described. Fragile $\mathrm{X}$ syndrome is caused by an expansion of CGG repeats greater than 200 in the fragile $\mathrm{X}$ mental retardation 1 gene (FMR1). ${ }^{38}$ Repeats falling within the range of 50 to 200 repeats are considered to be premutations and individuals in subsequent generations are at risk of further expansion. The prevalence of the premutation is approximately one in 700 males and one in 250 females. ${ }^{39}$ The initial report of the fragile $\mathrm{X}$ tremor/ataxia premutation syndrome consisted of case reports of five men over the age of 57 who were all grandfathers of children with fragile $\mathrm{X}$ syndrome. ${ }^{40}$ Several other reports have been published describing clinical, radiological, and pathological findings of other individuals with this disorder. Common neuroradiological findings include increased T2 signal intensity in the middle cerebellar peduncles and deep white matter of the cerebellum as well as diffuse cerebral and cerebellar atrophy. Neuropathological examination has revealed the presence of intranuclear inclusions in the neuronal and astrocytic nuclei of the cortex. ${ }^{41-45}$ The diagnostic utility of testing for this disorder in patients presenting with SCA has not yet been established.

The main objective of the present study was to determine the distribution of the hereditary spinocerebellar ataxias in patients who are followed at the University of Calgary Movement Disorders Clinic. The proportion of patients who had a family history suggestive of other affected individuals with a similar disorder was examined and the yield of genetic testing in patients with and without a positive family history was determined. In addition the SCA group was assessed for the frequency of the FMR1 premutation.

\section{METHODS}

Patients were identified by a search of the University of Calgary Movement Disorders Clinic patient registry for the diagnoses of spinocerebellar ataxia, Friedreich ataxia (FA), and multiple system atrophy-olivopontocerebellar atrophy. The geographical patient catchment area includes southern Alberta, south-western Saskatchewan, and south-eastern British Columbia. The majority of patients seen in the clinic live in the southern Alberta area.

Patients who had been seen between January 1, 1996 and December 31, 2002 were included in this study. Only those patients with an onset of symptoms at age 18 or greater were included. Individuals were excluded if they had a diagnosis of a secondary ataxia from disorders such as multiple sclerosis, brain tumour, paraneoplastic syndrome, stroke, or alcoholism. Patients seen for presymptomatic genetic testing were also excluded.

A detailed clinical chart review was performed, and the abstracted information was recorded on a standardized data collection form. The following variables were collected: gender, age of symptom onset, age at last assessment, presenting complaint, family history, neuroimaging findings, and the presence or absence of dysarthria, nystagmus, saccadic smooth pursuit, hyperreflexia, hyporeflexia, Babinski, spasticity, sensory findings, limb ataxia, Parkinsonism, dystonia, and autonomic symptoms. The aforementioned variables of interest were recorded as present if they were documented in the chart. If no information was documented, then the variables were recorded as absent.

Genetic testing for SCA1, SCA2, SCA3, SCA6, SCA7, SCA8, FA, DRPLA and the FMR1 expansion was performed in the Molecular Diagnostics Laboratory of the Alberta Children's Hospital in Calgary, Alberta using standard testing methods as previously published. . $, 3,6-9,12,-15,38$ A test was labelled positive if a repeat expansion in the pathological range was discovered. The number of tests performed in each of the families varied because not all of these tests became available at the same time. Testing using newly offered tests was only carried out if prior testing did not provide a specific genetic diagnosis.

Testing for DRPLA was part of the SCA assessment in our clinic initially but, as all patients were negative and the yield in non-Asian populations has been shown to be negligible, we have stopped doing this on a regular basis. ${ }^{46,47}$

Family history was divided into the following categories: autosomal dominant, autosomal recessive, positive but unknown, and adopted/unavailable. Autosomal dominant inheritance was assigned if at least two generations were affected and there was evidence of parent to child transmission. Autosomal recessive pedigrees were those that had affected siblings without other family history of a similar disorder, or if there were other similarly affected family members (e.g. cousins) without evidence of parent-child transmission. Some pedigrees contained family members who could possibly have had similar symptoms but adequate clinical information was not available. Such cases were labelled as positive but unknown inheritance. Relatives of the index cases were examined if available and attempts were made to obtain their medical records.

\section{RESULTS}

A total of 69 patients in 60 families were identified as having an adult onset spinocerebellar ataxia. Thirty three $(47.8 \%)$ of the study patients were male and $36(52.1 \%)$ were female. The mean age of symptom onset was 46.5 years with a range of 18 to 85 years. The mean duration of disease symptoms at the last followup visit was 11.7 years with a range of one to 44 years.

Thirty-two $(53.3 \%)$ of individuals studied had a positive family history with the majority (35\%) being autosomal dominant (see Table 2 for full description). Age of onset in the autosomal dominant and sporadic groups was twice that of the autosomal recessive group.

The results of genetic testing by family history classification are summarized in Table 3. The most common mutation in the autosomal dominant families was SCA3 (five families - 23.8\%). This was followed by SCA2 (three families $-14.3 \%$ ) and SCA6 (two families $-9.5 \%$ ). The SCA1 and SCA8 expansions were only identified in one family $(4.8 \%)$ each.

The DRPLA testing was done on 21 of the families and all results were negative.

Of the 44 families without a genetic diagnosis, two did not 
Table 2: Family History Category Among Study Families

\begin{tabular}{lll}
\hline Family History & $\mathbf{n}(\boldsymbol{\%})$ & Mean Age of Symptom Onset (Years) \\
\hline Autosomal Dominant & $21(35.0)$ & $43.2($ range $=18-72)$ \\
\hline Autosomal Recessive & $2(3.3)$ & $28.3($ range $=22-35)$ \\
\hline Positive but Undefined & $9(15.0)$ & $54.6($ range $=42-64)$ \\
\hline Sporadic & $26(43.3)$ & $49.4($ range $=20-85)$ \\
\hline Adopted & $2(3.3)$ & $47.5($ range $=30-65)$ \\
\hline Total & $60(100)$ & $46.5($ range $=18-85)$ \\
\hline
\end{tabular}

have DNA available for FMR1 testing. The index cases of the remaining 42 (22 males and 20 females) were tested for the FMR1 premutation. No premutation or pathological range expansions of the FMR1 gene were found. The highest number of repeats found was 38 .

Although the family history was suggestive of a dominant disorder, one patient was found to have FA. A patient in one of the two autosomal recessive appearing families tested positive for FA.

One of nine individuals $(11.1 \%)$ with a positive but undefined family history tested positive for SCA6. Two of his eight sisters also had an ataxic syndrome. This patient's mother died at age 89 with no gait abnormality and his father died at age 85 and had walked with a cane for a long time because of a supposed injury. As it was unclear whether he was affected the undefined category was chosen. It can be postulated that he was indeed affected.

Only one of the $26(3.8 \%)$ sporadic patients had a positive test. This individual tested positive for SCA3. The age of onset of symptoms was 22 years and the expanded allele contained 80 repeats. His father died of cancer at age 61 . His mother and seven siblings were all asymptomatic, and all tested negative for SCA3. None of his father's six siblings were known to be similarly affected. His mother had four siblings and none of them had any symptoms suggestive of a neurological disorder. It is suspected that this represented a new mutation, although paternity testing was not done.

One patient was found to be heterozygous for the Friedreich ataxia GAA expansion. Symptoms of gait dysfunction began at age 66 and other clinical features included dysarthria, nystagmus, saccadic smooth pursuit, hyporeflexia, as well symptoms of autonomic dysfunction. Sensory abnormalities were not noted. Sequencing of the coding region of the normal sized allele was performed in this individual as some patients with Friedreich ataxia are compound heterozygotes with an expansion on one allele and a point mutation on the other. ${ }^{48}$ No mutations were found in the normal sized allele of this patient. The normal sized allele was sequenced and no mutations were identified in the coding regions. The expansion was felt to be an incidental finding.

A positive test result was found in $61.9 \%$ (13/21) of autosomal dominant pedigrees, one out of two autosomal recessive pedigrees, and one of nine patients with positive but undefined family histories. Of those patients who lacked a family history of a similar disorder, only $1 / 26(3.8 \%)$ was found to have a positive genetic test. Neither of the two adopted patients had a positive test (Table 3).

The clinical features of all the patients separated by diagnosis

Table 3: Results of Genetic Testing - Families (\%)

\begin{tabular}{|c|c|c|c|c|c|c|}
\hline Genetic Test & AD & $\mathbf{A R}$ & Undefined & Sporadic & Adopted & Total \\
\hline SCA1 & $1(4.8)$ & 0 & 0 & 0 & 0 & $1(1.7)$ \\
\hline SCA2 & $3(14.3)$ & 0 & 0 & 0 & 0 & $3(5.0)$ \\
\hline$\overline{\mathrm{SCA} 3}$ & $5(23.8)$ & 0 & 0 & $1(3.8)$ & 0 & $6(10.0)$ \\
\hline SCA6 & $2(9.5)$ & 0 & 1(11.1) & 0 & 0 & $3(5.0)$ \\
\hline SCA7 & 0 & 0 & 0 & 0 & 0 & 0 \\
\hline SCA8 & $1(4.8)$ & 0 & 0 & 0 & 0 & $1(1.7)$ \\
\hline FA & $1(4.8)$ & $1(50)$ & 0 & 0 & 0 & $2(3.3)$ \\
\hline DRPLA & 0 & 0 & 0 & 0 & 0 & 0 \\
\hline FMR1 & 0 & 0 & 0 & 0 & 0 & 0 \\
\hline All Negative & $8(38.1)$ & $1(50)$ & $8(88.9)$ & $25(96.2)$ & $2(100)$ & $44(73.3)$ \\
\hline Total & $21(100)$ & $2(100)$ & $9(100)$ & $26(100)$ & $2(100)$ & $60(100)$ \\
\hline
\end{tabular}

$\mathrm{AD}=$ Autosomal Dominant $\mathrm{AR}=$ Autosomal Recessive 
Table 4: Clinical Features of Study Patients Separated by Diagnosis

\begin{tabular}{|c|c|c|c|c|c|c|c|}
\hline & SCA1 & SCA2 & SCA3 & SCA6 & SCA8 & FA & Other \\
\hline$\underline{\mathrm{n}}$ & 2 & 3 & 7 & 7 & 1 & 2 & 47 \\
\hline Male & 0 & 1 & 5 & 4 & 0 & 0 & 23 \\
\hline Female & 2 & 2 & 2 & 3 & 1 & 2 & 24 \\
\hline Mean Age of Onset (Years) & 44.5 & 33.0 & 36.3 & 55.9 & 29 & 21.5 & 49.0 \\
\hline Range of age of Onset & $39-50$ & $18-54$ & $22-55$ & $48-64$ & 29 & $21-22$ & $18-85$ \\
\hline $\begin{array}{l}\text { Mean Duration of Symptoms } \\
\text { at Last Visit (Years) }\end{array}$ & 17 & 23.3 & 10.7 & 7 & 15 & 13 & 11.4 \\
\hline Range of Symptom Duration & $9-25$ & $15-31$ & $4-19$ & $1-12$ & 15 & $10-16$ & $1-44$ \\
\hline Presenting Complaint Gait & $2 / 2$ & $2 / 3$ & $7 / 7$ & $6 / 7$ & $1 / 1$ & $2 / 2$ & $35 / 47$ \\
\hline Dysarthria & $2 / 2$ & $2 / 3$ & $6 / 7$ & $4 / 7$ & $1 / 1$ & $2 / 2$ & $35 / 47$ \\
\hline Nystagmus & $2 / 2$ & $1 / 3$ & $5 / 7$ & $6 / 7$ & $1 / 1$ & $2 / 2$ & $23 / 47$ \\
\hline Saccadic Smooth Pursuit & $2 / 2$ & $2 / 3$ & $5 / 7$ & $6 / 7$ & $1 / 1$ & $1 / 2$ & $36 / 47$ \\
\hline Hyperreflexia & $2 / 2$ & $1 / 3$ & $4 / 7 * *$ & $1 / 7$ & $0 / 1$ & $0 / 2$ & $30 / 47$ \\
\hline Hyporeflexia & $0 / 2$ & $1 / 3$ & $4 / 7 * *$ & $4 / 7$ & $1 / 1$ & $2 / 2$ & $11 / 47$ \\
\hline Babinski & $1 / 2$ & $0 / 3$ & $4 / 7$ & $0 / 7$ & $0 / 1$ & $1 / 2$ & $9 / 47$ \\
\hline Spasticity & $2 / 2$ & $0 / 3$ & $5 / 7$ & $1 / 7$ & $0 / 1$ & $0 / 2$ & $18 / 47$ \\
\hline Sensory Findings & $2 / 2$ & $1 / 3$ & $5 / 7$ & $1 / 7$ & $0 / 1$ & $2 / 2$ & $21 / 47$ \\
\hline Limb Ataxia & $2 / 2$ & $3 / 3$ & $5 / 7$ & $7 / 7$ & $1 / 1$ & $2 / 2$ & $38 / 47$ \\
\hline Parkinsonism & $0 / 2$ & $0 / 3$ & $3 / 7$ & $0 / 7$ & $0 / 1$ & $0 / 2$ & $7 / 47$ \\
\hline Dystonia & $1 / 2$ & $1 / 3$ & $3 / 7$ & $0 / 7$ & $1 / 1$ & $0 / 2$ & $2 / 47$ \\
\hline Chorea & $0 / 2$ & $0 / 3$ & $0 / 7$ & $0 / 7$ & $0 / 1$ & $0 / 2$ & $2 / 47$ \\
\hline Autonomic Symptoms & $0 / 2$ & $0 / 3$ & $1 / 7$ & $0 / 7$ & $0 / 1$ & $0 / 2$ & $7 / 47$ \\
\hline
\end{tabular}

** One patient had a mixture of hyporeflexia and hyperreflexia on the most recent physical examination that was documented in the chart.

Table 5: Distribution of the SCAs in Dominant Pedigrees of Different Populations

\section{Frequency $\%$}

\begin{tabular}{|c|c|c|c|c|c|c|c|c|c|c|}
\hline Country & $\begin{array}{c}\# \text { of } \\
\text { Families }\end{array}$ & SCA1 & SCA2 & SCA3 & SCA6 & SCA7 & SCA8 & SCA12 & DRPLA & Unclassified \\
\hline Australia $^{49}$ & 88 & 16 & 6 & 12 & 17 & 2 & - & - & - & 47 \\
\hline $\mathrm{USA}^{50}$ & 178 & 5.6 & 15.2 & 20.8 & 15.2 & 4.5 & - & - & - & 38.7 \\
\hline $\mathrm{USA}^{51,52}$ & 53 & 4 & 8 & 14.7 & 12 & - & - & - & 0 & 61.3 \\
\hline Germany ${ }^{53}$ & 77 & 9 & 10 & 42 & 22 & - & - & - & - & 17 \\
\hline Italy $^{54}$ & 32 & 19 & 31 & 3 & 0 & 0 & 0 & 0 & - & 47 \\
\hline Italy $^{55}$ & 73 & 41 & 29 & 0 & 0 & - & - & - & - & 30 \\
\hline Spain $^{56}$ & 87 & 5.6 & 15.3 & 15.3 & 1.4 & 2.8 & - & - & 1.4 & 57.3 \\
\hline Brazil $^{57}$ & 52 & 0 & 0 & 92 & 0 & 2 & 0 & - & 0 & 6 \\
\hline Portugal $^{58}$ & 46 & 0 & 4 & 74 & 0 & - & - & - & - & 22 \\
\hline Taiwan $^{59}$ & 74 & 5.4 & 10.8 & 47.3 & 10.8 & 2.7 & 0 & - & 1.4 & 21.6 \\
\hline China $^{60}$ & 85 & 4.7 & 5.9 & 48.2 & 0 & 0 & - & - & 0 & 41.2 \\
\hline Korea $^{61}$ & 32 & 6.3 & 31.3 & 28.1 & 6.3 & 3.1 & - & - & - & 25.0 \\
\hline Japan-Hokkaido $^{62}$ & $\begin{array}{ll}62 & 155 \\
\end{array}$ & 9.7 & 7.7 & 23.9 & 29.0 & 0 & 0 & - & 2.6 & 27.1 \\
\hline Japan-Honshu ${ }^{63}$ & 117 & 24.8 & 0.8 & 23.9 & 10.3 & 1.7 & 0.8 & - & 14.5 & 23.1 \\
\hline Japan-Kinki ${ }^{64}$ & 220 & 3.5 & 4.9 & 24.5 & 31.5 & 0 & 0 & 0 & 12.6 & 23 \\
\hline India-East ${ }^{65}$ & 57 & 10.5 & 17.5 & 7.0 & 1.8 & 0 & - & - & 0 & 73.2 \\
\hline $\begin{array}{l}\text { India-East \& } \\
\text { North }^{66}\end{array}$ & 39 & 7.7 & 25.6 & 5.1 & 0 & 0 & 0 & - & 0 & 61.5 \\
\hline This Study & 21 & 4.8 & 14.3 & 23.8 & 9.5 & 0 & 4.8 & - & 0 & 38.1 \\
\hline
\end{tabular}


are summarized in Table 4. All patients had an ataxic gait. Considerable variability existed between, as well as within, each of the diagnostic categories. Dysarthria, extraocular movement abnormalities, and reflex changes were commonly found in all groups. Parkinsonism, dystonia, Babinski, and autonomic symptoms were uncommon. A much younger age of onset of symptoms was noted in the two patients diagnosed with Friedreich ataxia.

\section{DISCUSSION}

The distribution of the spinocerebellar ataxias found in dominant pedigrees in other countries is summarized in Table 5. In the University of Calgary Movement Disorders Clinic population the most common SCA diagnosed by genetic testing is SCA3 followed by SCA2 and SCA6. The frequency of the different SCAs depends on ethnic and geographic factors. The finding that this genetic profile is most similar to that found in the United States and Germany is not surprising given that the population of southern Alberta is largely of European descent. ${ }^{49-}$ ${ }^{66}$ In the 2001 Canadian census $17.5 \%$ of the population of Calgary consisted of visible minorities. ${ }^{67}$ Changing patterns of immigration to Canada may result in an alteration of the relative frequencies of the SCAs over time.

Not included in the above analysis are two brothers followed in this clinic from the family described by Furtado et al (2002). ${ }^{68}$ These individuals presented with a levodopa responsive parkinsonian syndrome rather than an ataxia and were subsequently found to have the SCA2 mutation. Other reports of similar parkinsonian SCA2 phenotypes exist. ${ }^{69,70}$ Given that there may be a small but significant number of patients who carry the SCA2 expansion who manifest their illness with Parkinsonism or other non-ataxic problems, the specific prevalence of SCA2 in the population may be higher than this and other studies have suggested.

Just over half of our SCA patients have positive family histories and most of these pedigrees are autosomal dominant. The dominant spinocerebellar ataxias have rapidly expanded from disorders classified into a handful of clinical groups to 20 or more separate genetic entities. Even though testing is only available for a few of these disorders, current testing was able to provide a genetic diagnosis in $61.9 \%$ of the dominant pedigrees in our clinic.

While some dominant pedigrees may be easily apparent, a clinician may find that it is difficult to accurately classify the patient's family history in other cases. This may occur because the patient knows few details of family members' medical problems. Vague complaints may have been attributed correctly or incorrectly to another disorder such as back problems or old age. The tendency for the nucleotide repeat disorders to expand in successive generations with earlier age of onset and more severe symptoms may also result in a lack of evidence of clear parental involvement. The importance of examining all available family members, deemed clinically affected or unaffected, in order to determine who else is truly affected cannot be overemphasised.

Recessive spinocerebellar ataxias with onset in adulthood are much less common than dominant forms. The few patients with recessive pedigrees found in this clinic were significantly younger than the dominant and sporadic patients, with one of the patients testing positive for FA. While patients with FA usually present during childhood, onset of symptoms has been described to occur in the adult age group..$^{71-75}$ There is a report of symptom onset as high as 67 years. ${ }^{76}$ Testing for FA in adult onset patients appears to be appropriate.

The expanded FA gene was also found in a couple of less characteristic situations. One of the two patients found to have FA appeared to have an autosomal dominant disorder. The appearance of FA in two successive generations has been previously described. This occurs as a result of an affected homozygous individual having children with a heterozygous carrier. $^{77,78}$

One patient in the sample was found to be heterozygous for the FA GAA expansion. Given that the carrier frequency for the FA expansion is approximately one in 90, the appearance of one heterozygote in a sample of this size is appropriate. ${ }^{79,80}$

Just under half of our SCA patients lacked a positive family history. These individuals had ages of onset that were similar to those of the autosomal dominant patients. The etiology of SCA in these sporadic cases was not clear, and may represent a nongenetic disorder.

Testing of apparently sporadic cases only yielded one positive result. Several possible explanations exist for the appearance of a positive test result in an individual with a negative family history. As anticipation is a feature of most of these disorders, a positive family history may not be evident as an affected parent may have died before manifesting symptoms of the disorder. Symptoms may not be sufficient to enable the index case to realize that similar problems exist in family members. In addition, a large but normal allele or an allele in the indeterminate range might expand sufficiently to cause symptoms. The possibility of non-paternity can always cloud pedigree analysis.

While a positive result has been reported in as many as $22 \%$ of sporadic patients tested for the inheritable ataxias, the single individual testing positive out of 26 tested in this study is somewhat lower than most other studies. ${ }^{50-52,54,56,57,59-61,64,81-83}$ Our lower yield in this group may be the result of a more aggressive assessment of the family history resulting in fewer patients being classified as sporadic. Overall, one can see that the testing of apparent sporadic patients results in a small but potentially significant positive result rate. Testing in these individuals is important as the discovery that a patient's disorder is genetic has significant implications for other family members. Given the lack of positive results in our patients and the reported rarity in patents of European descent, DRPLA testing appears to be of little value for non-Japanese patients presenting with spinocerebellar ataxia. ${ }^{46,47}$ Testing might be more appropriate in individuals who have the additional features of chorea, dementia, or epilepsy.

There has been increasing interest in the role that premutation range expansions of the FMR1 gene has in degenerative disorders characterized by tremor, ataxia, Parkinsonism, and dementia. While no FMR1 premutations were found in our SCA patient population, there has been one other study which looked for its presence in a group of patients referred with SCA. Macpherson et al $^{84}$ tested 59 SCA patients who had tested negative for SCA types 1, 2, 3, 6, and 7. They found three with repeats in the premutation range. One of the patients had onset of 
ataxia at age ten. Another group reported testing for the FMR1 premutation in nine males and four females with the ataxic form of multiple system atrophy. While they did not find any repeats greater than 50, they felt that there was an excess of repeats greater than $40 .{ }^{85}$ There has been one report of two females with the association of tremor and ataxia with the FMR1 premutation. ${ }^{86}$ While females carrying the full mutation have been thought to have no clinical manifestations, $16 \%$ of women with the premutation develop premature menopause. ${ }^{87}$

At present, it appears that the fragile $\mathrm{X}$ premutation is only occasionally identified in patients presenting with SCA. Given that the prevalence of the premutation is relatively common (approximately one in 700 males and one in 250 females) and that as many as $20 \%$ of male premutation carriers over the age of 50 have symptoms suggestive of this disorder, one might wonder why the yield of testing SCA patients is not higher. ${ }^{88}$ Perhaps this disorder is much less common than has been suggested or additional genetic and/or environmental factors play a role in its development. It is possible that features other than the ataxia may be more prominent leading to diagnoses such as essential tremor, Parkinson's disease, or dementia. In addition, the white matter abnormalities might be interpreted as being indicative of a demyelinating disorder. The role that this syndrome plays in degenerative neurological disease should be investigated in a larger series of patients with these types of disorders.

In the University of Calgary Movement Disorders Clinic the most commonly diagnosed autosomal dominant spinocerebellar ataxia is SCA3 followed by SCA2 and SCA6. Over $60 \%$ of autosomal dominant ataxia pedigrees can be given a specific genetic diagnosis using currently available testing methods. A patient with an unclear but positive family history may also obtain a positive test result. The yield of testing sporadic patients is low but may provide useful information for the patient and his or her family. The fragile X tremor/ataxia syndrome was not identified in our SCA patient population.

\section{REFERENCES}

1. Harding AE. Clinical features and classification of inherited ataxias. Adv Neurol 1993; 61:1-14.

2. Orr HT, Chung MY, Banfi S, et al. Expansion of an unstable trinucleotide CAG repeat in spinocerebellar ataxia type 1 . Nat Genet 1993; 4:221-226.

3. Imbert G, Saudou F, Yvert G, et al. Cloning of the gene for spinocerebellar ataxia 2 reveals a locus with high sensitivity to expanded CAG/glutamine repeats. Nat Genet 1996; 14:285-291.

4. Pulst SM, Nechiporuk A, Nechiporuk T, et al. Moderate expansion of a normally biallelic trinucleotide repeat in spinocerebellar ataxia type 2. Nat Genet 1996; 14:269-276.

5. Sanpei K, Takano H, Igarashi S, et al. Identification of the spinocerebellar ataxia type 2 gene using a direct identification of repeat expansion and cloning technique, DIRECT. Nat Genet 1996; 14:277-284.

6. Kawaguchi Y, Okamoto T, Taniwaki M, et al. CAG expansions in a novel gene for Machado-Joseph disease at chromosome 14q32.1. Nat Genet 1994; 8:221-228.

7. Zhuchenko O, Bailey J, Bonnen $\mathrm{P}$, et al. Autosomal dominant cerebellar ataxia (SCA6) associated with small polyglutamine expansions in the alpha 1A-voltage-dependent calcium channel. Nat Genet 1997; 15:62-69.

8. Lindblad K, Savontaus ML, Stevanin G, et al. An expanded CAG repeat sequence in spinocerebellar ataxia type 7. Genome Res 1996; 6:965-971.

9. David G, Abbas N, Stevanin G, et al. Cloning of the SCA7 gene reveals a highly unstable CAG repeat expansion. Nat Genet 1997; 17:65-70.
10. Zuhlke C, Hellenbroich Y, Dalski A, et al. Different types of repeat expansion in the TATA-binding protein gene are associated with a new form of inherited ataxia. Eur J Hum Genet 2001; 9:160164.

11. Nakamura K, Jeong SY, Uchihara T, et al. SCA17, a novel autosomal dominant cerebellar ataxia caused by an expanded polyglutamine in TATA-binding protein. Hum Mol Genet 2001; 10:1441-1448.

12. Koide R, Ikeuchi T, Onodera O, et al. Unstable expansion of CAG repeat in hereditary dentatorubral-pallidoluysian atrophy (DRPLA). Nat Genet 1994; 6:9-13.

13. Holmes SE, O'Hearn EE, McInnis MG, et al. Expansion of a novel CAG trinucleotide repeat in the 5' region of PPP2R2B is associated with SCA12. Nat Genet 1999; 23:391-392.

14. Campuzano V, Montermini L, Molto MD, et al. Friedreich's ataxia: autosomal recessive disease caused by an intronic GAA triplet repeat expansion. Science 1996; 271:1423-1427.

15. Koob MD, Moseley ML, Schut LJ, et al. An untranslated CTG expansion causes a novel form of spinocerebellar ataxia (SCA8). Nat Genet 1999; 21:379-384.

16. Worth PF, Houlden H, Giunti P, Davis MB, Wood NW. Large, expanded repeats in SCA8 are not confined to patients with cerebellar ataxia. Nat Genet 2000; 24:214-215.

17. Vincent JB, Neves-Pereira ML, Paterson AD, et al. An unstable trinucleotide-repeat region on chromosome 13 implicated in spinocerebellar ataxia: a common expansion locus. Am J Hum Genet 2000; 66:819-829.

18. Schols L, Bauer I, Zuhlke C, et al. Do CTG expansions at the SCA8 locus cause ataxia? Ann Neurol 2003; 54:110-115.

19. Matsuura T, Yamagata T, Burgess DL, et al. Large expansion of the ATTCT pentanucleotide repeat in spinocerebellar ataxia type 10 . Nat Genet 2000; 26:191-194.

20. Flanigan K, Gardner K, Alderson K, et al. Autosomal dominant spinocerebellar ataxia with sensory axonal neuropathy (SCA4): clinical description and genetic localization to chromosome 16q22.1. Am J Hum Genet 1996; 59:392-399.

21. Nagaoka U, Takashima M, Ishikawa K, et al. A gene on SCA4 locus causes dominantly inherited pure cerebellar ataxia. Neurology 2000; 54:1971-1975.

22. Ranum LP, Schut LJ, Lundgren JK, Orr HT, Livingston DM. Spinocerebellar ataxia type 5 in a family descended from the grandparents of President Lincoln maps to chromosome 11. Nat Genet 1994; 8:280-284.

23. Worth PF, Giunti P, Gardner-Thorpe C, et al. Autosomal dominant cerebellar ataxia type III: linkage in a large British family to a 7.6-cM region on chromosome 15q14-21.3. Am J Hum Genet 1999; 65:420-426.

24. Herman-Bert A, Stevanin G, Netter JC, et al. Mapping of spinocerebellar ataxia 13 to chromosome 19q13.3-q13.4 in a family with autosomal dominant cerebellar ataxia and mental retardation. Am J Hum Genet 2000; 67:229-235.

25. Yamashita I, Sasaki H, Yabe I, et al. A novel locus for dominant cerebellar ataxia (SCA14) maps to a 10.2-cM interval flanked by D19S206 and D19S605 on chromosome 19q13.4-qter. Ann Neurol 2000; 48:156-163.

26. Brkanac Z, Bylenok L, Fernandez M, et al. A new dominant spinocerebellar ataxia linked to chromosome 19q13.4-qter. Arch Neurol 2002; 59:1291-1295.

27. Miyoshi Y, Yamada T, Tanimura M, et al. A novel autosomal dominant spinocerebellar ataxia (SCA16) linked to chromosome 8q22.1-24.1. Neurology 2001; 57:96-100.

28. Brkanac Z, Fernandez M, Matsushita M, et al. Autosomal dominant sensory/motor neuropathy with Ataxia (SMNA): Linkage to chromosome 7q22-q32. Am J Med Genet 2002; 114:450-457.

29. Verbeek DS, Schelhaas JH, Ippel EF, et al. Identification of a novel SCA locus ( SCA19) in a Dutch autosomal dominant cerebellar ataxia family on chromosome region 1p21-q21. Hum Genet 2002; 111:388-393.

30. Vuillaume I, Devos D, Schraen-Maschke S, et al. A new locus for spinocerebellar ataxia (SCA21) maps to chromosome 7p21.3p15.1. Ann Neurol 2002; 52:666-670.

31. Chung MY, Lu YC, Cheng NC, Soong BW. A novel autosomal dominant spinocerebellar ataxia (SCA22) linked to chromosome 1p21-q23. Brain 2003; 126:1293-1299. 
32. Stevanin G, Bouslam N, Thobois S, et al. Spinocerebellar ataxia with sensory neuropathy (SCA25) maps to chromosome 2p. Ann Neurol 2004; 55:97-104.

33. Knight MA, Gardner RJ, Bahlo M, et al. Dominantly inherited ataxia and dysphonia with dentate calcification: spinocerebellar ataxia type 20. Brain 2004; 127:1172-1181.

34. Hara K, Fukushima T, Suzuki T, et al. Japanese SCA families with an unusual phenotype linked to a locus overlapping with SCA15 locus. Neurology 2004; 62:648-651.

35. HUGO Gene Nomenclature Committee: (Accessed December 5, 2004 at http://www.gene.ucl.ac.uk/nomenclature/).

36. Swartz BE, Burmeister M, Somers JT, Ret al. A form of inherited cerebellar ataxia with saccadic intrusions, increased saccadic speed, sensory neuropathy, and myoclonus. Ann N Y Acad Sci 2002; 956:441-444.

37. Online Mendelian Inheritance in Man: (Accessed December 5, 2004 at http://www.ncbi.nlm.nih.gov/entrez/query.fcgi?db=OMIM).

38. Kremer EJ, Pritchard M, Lynch M, et al. Mapping of DNA instability at the fragile $\mathrm{X}$ to a trinucleotide repeat sequence p(CCG)n. Science 1991; 252:1711-1714.

39. Rousseau F, Rouillard P, Morel ML, Khandjian EW, Morgan K. Prevalence of carriers of premutation-size alleles of the FMRI gene--and implications for the population genetics of the fragile X syndrome. Am J Hum Genet 1995; 57:1006-1018.

40. Hagerman RJ, Leehey M, Heinrichs W, et al. Intention tremor, parkinsonism, and generalized brain atrophy in male carriers of fragile X. Neurology 2001; 57:127-130.

41. Greco CM, Hagerman RJ, Tassone F, et al. Neuronal intranuclear inclusions in a new cerebellar tremor/ataxia syndrome among fragile X carriers. Brain 2002; 125:1760-1771.

42. Jacquemont $S$, Hagerman RJ, Leehey $M$, et al. Fragile $X$ premutation tremor/ataxia syndrome: molecular, clinical, and neuroimaging correlates. Am J Hum Genet 2003; 72:869-878.

43. Leehey MA, Munhoz RP, Lang AE, et al. The fragile X premutation presenting as essential tremor. Arch Neurol 2003; 60:117-121.

44. Munoz DG. Intention tremor, parkinsonism, and generalized brain atrophy in male carriers of fragile X. Neurology 2002; 58:987; author reply 987-988.

45. Brunberg JA, Jacquemont S, Hagerman RJ, et al. Fragile X premutation carriers: characteristic MR imaging findings of adult male patients with progressive cerebellar and cognitive dysfunction. AJNR Am J Neuroradiol 2002; 23:1757-1766.

46. Silveira I, Lopes-Cendes I, Kish S, et al. Frequency of spinocerebellar ataxia type 1, dentatorubropallidoluysian atrophy, and Machado-Joseph disease mutations in a large group of spinocerebellar ataxia patients. Neurology 1996; 46:214-218.

47. Warner TT, Lennox GG, Janota I, Harding AE. Autosomaldominant dentatorubropallidoluysian atrophy in the United Kingdom. Mov Disord 1994; 9:289-296.

48. Cossee M, Durr A, Schmitt M, et al. Friedreich's ataxia: point mutations and clinical presentation of compound heterozygotes. Ann Neurol 1999; 45:200-206.

49. Storey E, du Sart D, Shaw JH, et al. Frequency of spinocerebellar ataxia types $1,2,3,6$, and 7 in Australian patients with spinocerebellar ataxia. Am J Med Genet 2000; 95:351-357.

50. Moseley ML, Benzow KA, Schut LJ, et al. Incidence of dominant spinocerebellar and Friedreich triplet repeats among 361 ataxia families. Neurology 1998; 51:1666-1671.

51. Geschwind DH, Perlman S, Figueroa KP, Ket al. Spinocerebellar ataxia type 6 . Frequency of the mutation and genotype-phenotype correlations. Neurology 1997; 49:1247-1251.

52. Geschwind DH, Perlman S, Figueroa CP, Treiman LJ, Pulst SM. The prevalence and wide clinical spectrum of the spinocerebellar ataxia type 2 trinucleotide repeat in patients with autosomal dominant cerebellar ataxia. Am J Hum Genet 1997; 60:842-850.

53. Schols L, Amoiridis G, Buttner T, Pet al. Autosomal dominant cerebellar ataxia: phenotypic differences in genetically defined subtypes? Ann Neurol 1997; 42:924-932.

54. Cellini E, Forleo P, Nacmias B, et al. Clinical and genetic analysis of hereditary and sporadic ataxia in central Italy. Brain Res Bull 2001; 56:363-366.
55. Pareyson D, Gellera C, Castellotti B, et al. Clinical and molecular studies of 73 Italian families with autosomal dominant cerebellar ataxia type I: SCA1 and SCA2 are the most common genotypes. J Neurol 1999; 246:389-393.

56. Pujana MA, Corral J, Gratacos M, et al. Spinocerebellar ataxias in Spanish patients: genetic analysis of familial and sporadic cases. The Ataxia Study Group. Hum Genet 1999; 104:516-522.

57. Jardim LB, Silveira I, Pereira ML, et al. A survey of spinocerebellar ataxia in South Brazil - 66 new cases with Machado-Joseph disease, SCA7, SCA8, or unidentified disease-causing mutations. J Neurol 2001; 248:870-876.

58. Silveira I, Coutinho P, Maciel P, et al. Analysis of SCA1, DRPLA, MJD, SCA2, and SCA6 CAG repeats in 48 Portuguese ataxia families. Am J Med Genet 1998; 81:134-138.

59. Soong BW, Lu YC, Choo KB, Lee HY. Frequency analysis of autosomal dominant cerebellar ataxias in Taiwanese patients and clinical and molecular characterization of spinocerebellar ataxia type 6. Arch Neurol 2001; 58:1105-1109.

60. Tang B, Liu C, Shen L, et al. Frequency of SCA1, SCA2, SCA3/MJD, SCA6, SCA7, and DRPLA CAG trinucleotide repeat expansion in patients with hereditary spinocerebellar ataxia from Chinese kindreds. Arch Neurol 2000; 57:540-544

61. Kim JY, Park SS, Joo SI, Kim JM, Jeon BS. Molecular analysis of spinocerebellar ataxias in Koreans: frequencies and reference ranges of SCA1, SCA2, SCA3, SCA6, and SCA7. Mol Cells 2001; 12:336-341.

62. Sasaki H, Yabe I, Yamashita I, Tashiro K. Prevalence of triplet repeat expansion in ataxia patients from Hokkaido, the northernmost island of Japan. J Neurol Sci 2000; 175:45-51.

63. Onodera Y, Aoki M, Tsuda T, et al. High prevalence of spinocerebellar ataxia type 1 (SCA1) in an isolated region of Japan. J Neurol Sci 2000; 178:153-158.

64. Matsumura R, Futamura N, Ando N, Ueno S. Frequency of spinocerebellar ataxia mutations in the Kinki district of Japan. Acta Neurol Scand 2003; 107:38-41.

65. Basu P, Chattopadhyay B, Gangopadhaya PK, et al. Analysis of CAG repeats in SCA1, SCA2, SCA3, SCA6, SCA7 and DRPLA loci in spinocerebellar ataxia patients and distribution of CAG repeats at the SCA1, SCA2 and SCA6 loci in nine ethnic populations of eastern India. Hum Genet 2000; 106:597-604.

66. Saleem Q, Choudhry S, Mukerji M, et al. Molecular analysis of autosomal dominant hereditary ataxias in the Indian population: high frequency of SCA2 and evidence for a common founder mutation. Hum Genet 2000; 106:179-187.

67. Proportion of visible minorities, census metropolitan areas, 2001, 1996 and 1991: (Accessed July 6, 2003 at http://www12.statcan.ca/English/census01/products/analytic/co mpanion/etoimm/subprovs.cfm).

68. Furtado S, Farrer M, Tsuboi $\mathrm{Y}$, et al. SCA-2 presenting as parkinsonism in an Alberta family: clinical, genetic, and PET findings. Neurology 2002; 59:1625-1627.

69. Shan DE, Soong BW, Sun CM, et al. Spinocerebellar ataxia type 2 presenting as familial levodopa-responsive parkinsonism. Ann Neurol 2001; 50:812-815.

70. Gwinn-Hardy K, Chen JY, Liu HC, et al. Spinocerebellar ataxia type 2 with parkinsonism in ethnic Chinese. Neurology 2000; 55:800805.

71. De Michele G, Filla A, Barbieri F, et al. Late onset recessive ataxia with Friedreich's disease phenotype. J Neurol Neurosurg Psychiatry 1989; 52:1398-1401.

72. De Michele G, Filla A, Cavalcanti F, et al. Late onset Friedreich's disease: clinical features and mapping of mutation to the FRDA locus. J Neurol Neurosurg Psychiatry 1994; 57:977-979.

73. Gellera C, Pareyson D, Castellotti B, et al. Very late onset Friedreich's ataxia without cardiomyopathy is associated with limited GAA expansion in the X25 gene. Neurology 1997; 49:1153-1155

74. Bidichandani SI, Garcia CA, Patel PI, Dimachkie MM. Very lateonset Friedreich ataxia despite large GAA triplet repeat expansions. Arch Neurol 2000; 57:246-251.

75. Durr A, Cossee M, Agid Y, et al. Clinical and Genetic Abnormalities in Patients with Friedreich's Ataxia. N Engl J Med 1996; $335: 1169-1175$ 
76. McDaniel DO, Keats B, Vedanarayanan VV, Subramony SH. Sequence variation in GAA repeat expansions may cause differential phenotype display in Friedreich's ataxia. Mov Disord 2001; 16:1153-1158.

77. Harding AE, Zilkha KJ. 'Pseudo-dominant' inheritance in Friedreich's ataxia. J Med Genet 1981; 18:285-287.

78. Webb S, Doudney K, Pook M, Chamberlain S, Hutchinson M. A family with pseudodominant Friedreich's ataxia showing marked variation of phenotype between affected siblings. J Neurol Neurosurg Psychiatry 1999; 67:217-219.

79. Cossee M, Schmitt M, Campuzano V, et al. Evolution of the Friedreich's ataxia trinucleotide repeat expansion: founder effect and premutations. Proc Natl Acad Sci U S A 1997; 94:7452-7457.

80. Epplen C, Epplen JT, Frank G, et al. Differential stability of the (GAA)n tract in the Friedreich ataxia (STM7) gene. Hum Genet 1997; 99:834-836.

81. Schols L, Szymanski S, Peters S, et al. Genetic background of apparently idiopathic sporadic cerebellar ataxia. Hum Genet 2000; 107:132-137.

82. Abele M, Burk K, Schols L, et al. The aetiology of sporadic adultonset ataxia. Brain 2002; 125:961-968.

83. Futamura N, Matsumura R, Fujimoto Y, et al. CAG repeat expansions in patients with sporadic cerebellar ataxia. Acta Neurol Scand 1998; 98:55-59.

84. Macpherson J, Waghorn A, Hammans S, Jacobs P. Observation of an excess of fragile- $X$ premutations in a population of males referred with spinocerebellar ataxia. Hum Genet 2003; 112(5-6): 619-620.

85. Zhang L, Leehey M, Wheelock V, et al. A subtype of multiple system atrophy with cerebellar ataxia (MSA-C): The fragile Xassociated tremor/ataxia syndrome. (Abstract). Neurology 2003; 60:A331470.

86. Hagerman RJ, Zhang L, Brunberg J, et al. Two female cases of the fragile $\mathrm{X}$ premutation tremor/ataxia syndrome: cognitive, molecular and radiological studies. (Abstract). Neurology 2003; 60:A331.

87. Allingham-Hawkins DJ, Babul-Hirji R, Chitayat D, et al. Fragile X premutation is a significant risk factor for premature ovarian failure: the International Collaborative POF in Fragile X study-preliminary data. Am J Med Genet 1999; 83:322-325.

88. Rogers C, Partington MW, Turner GM. Tremor, ataxia and dementia in older men may indicate a carrier of the fragile $\mathrm{X}$ syndrome. Clin Genet 2003; 64:54-56.

89. Jackson JF, Currier RD, Terasaki PI, Morton NE. Spinocerebellar ataxia and HLA linkage: risk prediction by HLA typing. N Engl J Med 1977; 296:1138-1141.
90. Banfi S, Servadio A, Chung MY, et al. Identification and characterization of the gene causing type 1 spinocerebellar ataxia. Nat Genet 1994; 7:513-520.

91. Gispert S, Twells R, Orozco G, et al. Chromosomal assignment of the second locus for autosomal dominant cerebellar ataxia (SCA2) to chromosome 12q23-24.1. Nat Genet 1993; 4:295-299.

92. Orozco Diaz G, Nodarse Fleites A, Cordoves Sagaz R, Auburger G. Autosomal dominant cerebellar ataxia: clinical analysis of 263 patients from a homogeneous population in Holguin, Cuba. Neurology 1990; 40:1369-1375.

93. Coutinho P, Andrade C. Autosomal dominant system degeneration in Portuguese families of the Azores Islands. A new genetic disorder involving cerebellar, pyramidal, extrapyramidal and spinal cord motor functions. Neurology 1978; 28:703-709.

94. Tuite PJ, Rogaeva EA, St George-Hyslop PH, Lang AE. Doparesponsive parkinsonism phenotype of Machado-Joseph disease: confirmation of 14q CAG expansion. Ann Neurol 1995; 38:684687.

95. Takiyama Y, Nishizawa M, Tanaka H, et al. The gene for MachadoJoseph disease maps to human chromosome 14q. Nat Genet 1993; 4:300-304.

96. Schols L, Vieira-Saecker AM, Schols S, et al. Trinucleotide expansion within the MJD1 gene presents clinically as spinocerebellar ataxia and occurs most frequently in German SCA patients. Hum Mol Genet 1995; 4:1001-1005.

97. Nakano KK, Dawson DM, Spence A. Machado disease. A hereditary ataxia in Portuguese emigrants to Massachusetts. Neurology 1972; 22:49-55.

98. Giunti P, Stevanin G, Worth PF, et al. Molecular and clinical study of 18 families with ADCA type II: evidence for genetic heterogeneity and de novo mutation. Am J Hum Genet 1999; 64:1594-1603.

99. Matsuura T, Achari M, Khajavi M, et al. Mapping of the gene for a novel spinocerebellar ataxia with pure cerebellar signs and epilepsy. Ann Neurol 1999; 45:407-411.

100. Grewal RP, Tayag E, Figueroa KP, et al. Clinical and genetic analysis of a distinct autosomal dominant spinocerebellar ataxia. Neurology 1998; 51:1423-1426.

101. Storey E, Gardner RJ, Knight MA, et al. A new autosomal dominant pure cerebellar ataxia. Neurology 2001; 57:1913-1915.

102. Schelhaas HJ, Ippel PF, Hageman G, et al. Clinical and genetic analysis of a four-generation family with a distinct autosomal dominant cerebellar ataxia. J Neurol 2001; 248:113-120.

103. Devos D, Schraen-Maschke S, Vuillaume I, et al. Clinical features and genetic analysis of a new form of spinocerebellar ataxia. Neurology 2001; 56:234-238. 